\title{
An Observing System Simulation Experiment with a Constellation of Radio Occultation Satellites
}

\author{
L. CuCurull And R. Atlas \\ NOAA/Atlantic Oceanographic and Meteorological Laboratory, Miami, Florida \\ R. LI AND M. J. MUELLER \\ Cooperative Institute for Research in the Environmental Sciences, University of Colorado Boulder, and \\ NOAA/OAR/ESRL/Global Systems Division, Boulder, Colorado \\ R. N. HOFFMAN \\ Cooperative Institute for Marine and Atmospheric Studies, University of Miami, and NOAA/Atlantic \\ Oceanographic and Meteorological Laboratory, Miami, Florida
}

(Manuscript received 9 March 2018, in final form 17 August 2018)

\begin{abstract}
Experiments with a global observing system simulation experiment (OSSE) system based on the recent 7-km-resolution NASA nature run (G5NR) were conducted to determine the potential value of proposed Global Navigation Satellite System (GNSS) radio occultation (RO) constellations in current operational numerical weather prediction systems. The RO observations were simulated with the geographic sampling expected from the original planned Constellation Observing System for Meteorology, Ionosphere, and Climate-2 (COSMIC-2) system, with six equatorial (total of $\sim 6000$ soundings per day) and six polar (total of $\sim 6000$ soundings per day) receiver satellites. The experiments also accounted for the expected improved vertical coverage provided by the Jet Propulsion Laboratory RO receivers on board COSMIC-2. Except that RO observations were simulated and assimilated as refractivities, the 2015 version of the NCEP's operational data assimilation system was used to run the OSSEs. The OSSEs quantified the impact of RO observations on global weather analyses and forecasts and the impact of adding explicit errors to the simulation of perfect RO profiles. The inclusion or exclusion of explicit errors had small, statistically insignificant impacts on results. The impact of RO observations was found to increase the length of the useful forecasts. In experiments with explicit errors, these increases were found to be $0.6 \mathrm{~h}$ in the Northern Hemisphere extratropics (a $0.4 \%$ improvement), $5.9 \mathrm{~h}$ in the Southern Hemisphere extratropics (a significant $4.0 \%$ improvement), and $12.1 \mathrm{~h}$ in the tropics (a very substantial $28.4 \%$ improvement).
\end{abstract}

\section{Introduction}

Observing system simulation experiments (OSSEs) provide a unique framework to evaluate the impact of current and proposed or future observing systems (Atlas 1997; Atlas et al. 1985). While observing system experiments (OSEs) can be used to assess the value of existing observations, OSSEs enable a quantitative evaluation of proposed observing technologies. Different from the real-world scenario, the "truth" is known in the OSSE system, providing an effective technique to quantitatively evaluate the impact of observations in terms of

Corresponding author: Lidia Cucurull, lidia.cucurull@noaa.gov analysis and weather forecast skill. Although OSSEs can be used for a large variety of applications such as hurricanes (e.g., Atlas et al. 2015a,b) and ocean assimilation (Halliwell et al. 2014, 2015), this study focuses on global numerical weather prediction (NWP) applications.

In an OSSE, the true atmosphere (or "nature run") is typically represented by a long NWP model forecast. The nature run should represent the main characteristics of the atmosphere, and differences between the nature run and the forecast model used to conduct the impact studies should be similar to the differences that exist between a state-of-the art data assimilation system and the real atmosphere. Synthetic observations from current and proposed observing technologies are generated 
from the nature run by using appropriate forward operators, spatial and temporal coverage, and error characteristics. An overview of the OSSE methodology, as well as its recent and anticipated improvements and associated challenges, is provided by Hoffman and Atlas (2016).

To prioritize mission designs in a cost-effective way by analyzing tradeoffs in the formulation of proposed observing systems and thereby leading to a more effective observing system architecture, the U.S. Congress mandated NOAA to conduct an OSSE with Global Navigation Satellite System (GNSS) radio occultation (RO) observations. Additional motivations for testing additional constellations of RO observations include the following. First, RO is among the observing technologies making the largest contributions to improving global weather forecasting (e.g., Healy and Thépaut 2006; Cucurull and Derber 2008; Aparicio and Deblonde 2008; Rennie 2010; Anlauf et al. 2011; Cucurull et al. 2013). Second, the Constellation for Observing System for Meteorology, Ionosphere, and Climate (COSMIC), a six-satellite mission launched in 2006 (Rocken et al. 2000; Anthes et al. 2008), is already past the end of its nominal lifetime, and the number of observations has declined from $\sim 2000$ profiles per day to $\sim 250-300$ profiles per day. Third, this low-cost remote sensing technique has the capability to partially mitigate potential satellite observing gaps (Cucurull and Anthes 2015). Fourth, some commercial companies claim to be able to deliver accurate RO profiles for real-time applications at an affordable cost. Finally, since the RO measurement is a timing measurement, and observations are accurate and nearly unbiased-even in the presence of clouds and hydrometeors - and are available globally, the assimilation of RO observations in NWP enhances the benefits of assimilating microwave and infrared sounders by correcting biases in these data and reducing the model drift to its own biased climatology (Dee 2005; Healy et al. 2005; Healy and Thépaut 2006; Poli et al. 2010; Bauer et al. 2014; Cucurull et al. 2014; Bonavita 2014).

This paper evaluates the impact of a constellation of RO satellites in improving global NWP forecast skill at NOAA. In this study, RO observations were simulated with the geographic sampling expected from the originally planned COSMIC-2 constellation-the COSMIC follow-up mission - with six equatorial (total of $\sim 6000$ soundings per day) and six polar (total of $\sim 6000$ soundings per day) receiver satellites, assuring global data coverage. (The United States and Taiwan recently decided to not move forward with the polar component of the COSMIC-2 mission. The launch of the equatorial component of COSMIC-2 is planned for late 2018.) The experiments also account for the expected improved performance of the Jet Propulsion Laboratory RO receivers on board COSMIC-2.
In previous work, Cucurull et al. (2017) quantified the benefits of the equatorial and polar components of COSMIC-2 to improve global NWP skill by conducting a series of simplified OSSEs. Results showed that global distribution of the observations, as provided by the polar launch of COSMIC-2, is necessary to improve weather forecasts globally. That study used an older OSSE system, characterized by a lower-resolution nature run $(\sim 39 \mathrm{~km})$ provided by the European Centre for Medium-Range Weather Forecasts (ECMWF; Masutani et al. 2006), and an older version (2012 version) of the National Centers for Environmental Prediction (NCEP)'s operational data assimilation system. Furthermore, all simulated observations, including RO, were assumed to be perfect (i.e., with no added explicit errors). By contrast, the OSSEs described in the current study make use of a more advanced "next generation" OSSE system, and explicit errors are added to the simulated observations. Finally, the differences in impact in NWP between the assimilation of perfect and error-added RO observations are also quantified.

The structure of the paper is as follows. Section 2 describes the OSSE system and the design of the different experiments. Results with perfect and erroradded RO simulated observations are discussed in sections 3 and 4, respectively. Finally, the main conclusions are summarized in section 5 .

\section{Experiment design}

The nature run used in our OSSEs is based on the 7-km-resolution, nonhydrostatic Goddard Earth Observing System model, version 5 (GEOS-5; Putman et al. 2015). To generate the GEOS-5 nature run (G5NR), GEOS-5 was implemented on the c1440 cubed sphere with 72 model vertical layers and a model top of $1 \mathrm{~Pa}$ and run for a 2-yr period. A detailed description of the GEOS-5 setup used to generate the G5NR can be found in Putman et al. (2014).

The data assimilation system used in all the experiments was the 2015 version of the NCEP's operational suite, with the exception of the RO forward model as described below. The Global Forecast System (GFS) model ran at a lower horizontal resolution of T670 $(\sim 27 \mathrm{~km})$, but with the same number of vertical levels (64) as in the operational configuration. All the experiments used the hybrid three-dimensional (3D) ensemble-variational (EnVar) version of the NCEP's Gridpoint Statistical Interpolation analysis system (GSI) at a resolution of T254 $(\sim 50 \mathrm{~km})$, which includes the latest version of the variational bias-correction procedure (Zhu et al. 2014). The 80-member ensembles used in the hybrid data assimilation system also ran at a resolution of T254. 


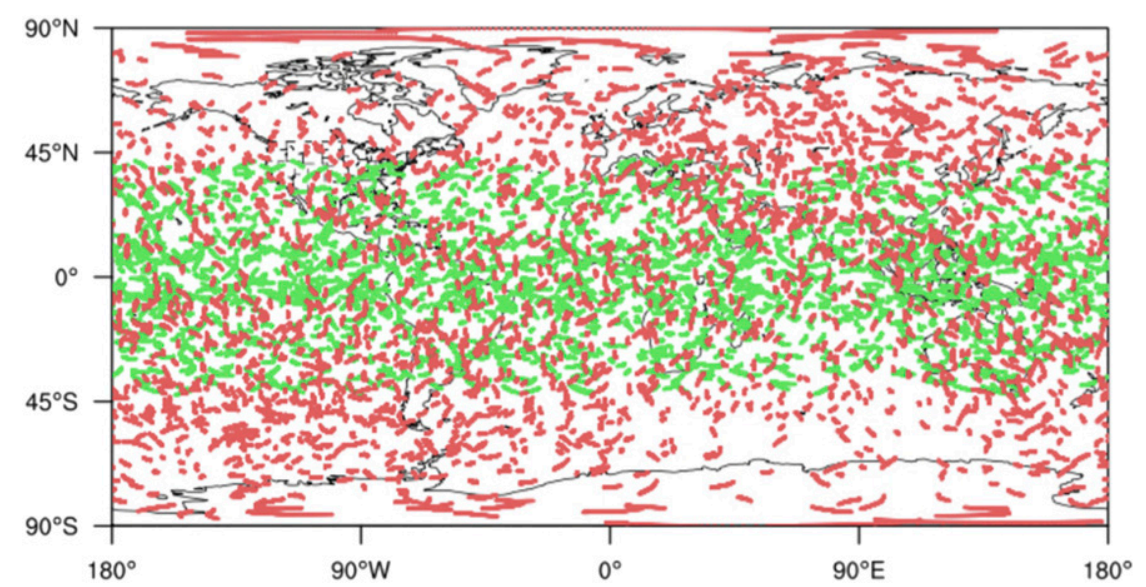

FIG. 1. Spatial distribution of the COSMIC-2 observations from equatorial (green) and polar (red) receiver satellites for a 6 -h assimilation time window.

Existing conventional and satellite radiance observations were simulated for August/September 2006 using the 2014 global observing system configuration following the procedures of Boukabara et al. (2016). Conventional observations were simulated by interpolating the nature run to the geographical locations of the real-world observations. The Community Radiative Transfer Model (CRTM), version 2.1.3 (Chen et al. 2008; Ding et al. 2011), was used as the forward operator to simulate clearsky satellite radiances. RO soundings of refractivity were simulated using the forward operator described by Cucurull (2010). Realistic satellite orbits were used to simulate COSMIC-2 soundings of refractivity from the GNSS transmitting satellites of the U.S. global positioning system (GPS) and the Russian Global Navigation Satellite System (GLONASS) constellations (Cucurull et al. 2017). Distribution of the COSMIC-2 refractivity soundings are shown in Cucurull et al. (2017, Fig. 1a), and the figure is reproduced here as Fig. 1.

Random errors were explicitly added to the simulated perfect observations following the methodology described by Errico et al. (2013). An iterative process is used to tune the observation random errors in order to match the observation minus background statistics from the OSSE system to the corresponding OSE statistics with real observations. Systematic errors were added to the satellite radiances using a similar approach (Boukabara et al. 2016). Error statistics for RO are determined in this way as a function of vertical level (Fig. 2a). Although, in reality, refractivity errors will be vertically correlated, such correlations are not included in either the simulation or assimilation process. The resulting tuned errors from the existing COSMIC satellites were used for the simulated RO constellation generated in this study. As examples, differences (in percentage) between perfect and error-added RO profiles at four different latitudes are shown in Fig. 3.

In terms of simulation and assimilation of the refractivity observations, the differences between the instrument observation errors of COSMIC and COSMIC-2 are expected to have no or little impact. This is the case because there are other contributions to the measurement error beyond the impact of the improved instrument precision expected in COSMIC-2 (i.e., ionospheric and clock corrections) that might prevent it from obtaining benefits of the lower instrument error (T. Meehan 2018, personal communication). Furthermore, currently, the combination of representativeness and forward model errors is much larger than the measurement error. As an example, the total RO observation error used in a 2-week experiment with COSMIC is shown in Fig. $2 b$ in bending angle space. This error ranges from $\sim 10-30 \mu \mathrm{rad}$ down to $\sim 10 \mathrm{~km}$, and it increases to $\sim 750 \mu \mathrm{rad}$ in the lower troposphere. The magnitude of the corresponding measurement error is $1-2 \mu \mathrm{rad}$ down to a height of 10-20 km (Schreiner et al. 2011; S. Sokolovskiy 2018, personal communication). All the error components increase below $10 \mathrm{~km}$. COSMIC-2 performance is expected to be at least as good as COSMIC (S. Sokolovskiy 2018, personal communication).

Quality control algorithms were modified in the experiments with COSMIC-2 observations to allow deeper penetration in the lower troposphere. This is expected to occur in reality because the COSMIC-2 improved signal-to-noise ratio (SNR) results in the ability to track the GNSS transmissions deeper in the atmosphere. Most benefits from COSMIC-2 performance over COSMIC are expected to come from better retrievals with a high percentage of soundings penetrating deeper into the lower tropical troposphere (T. Meehan 2018, personal 
a)

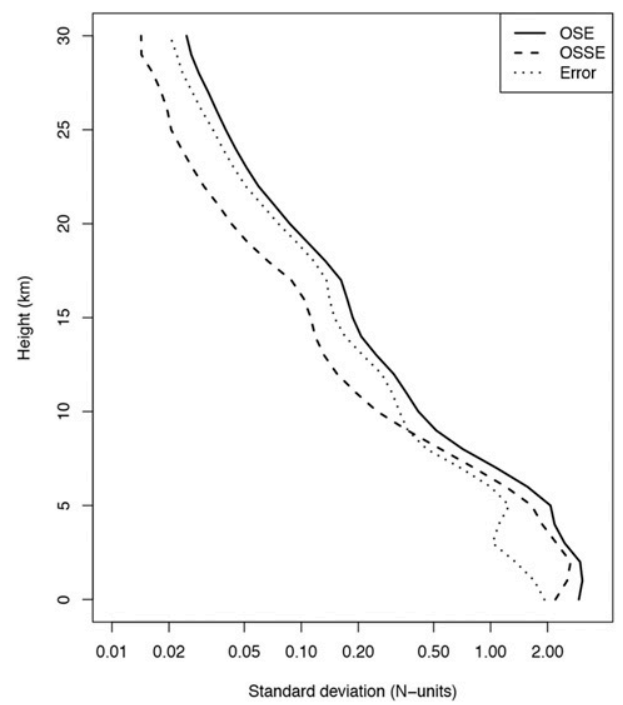

b)

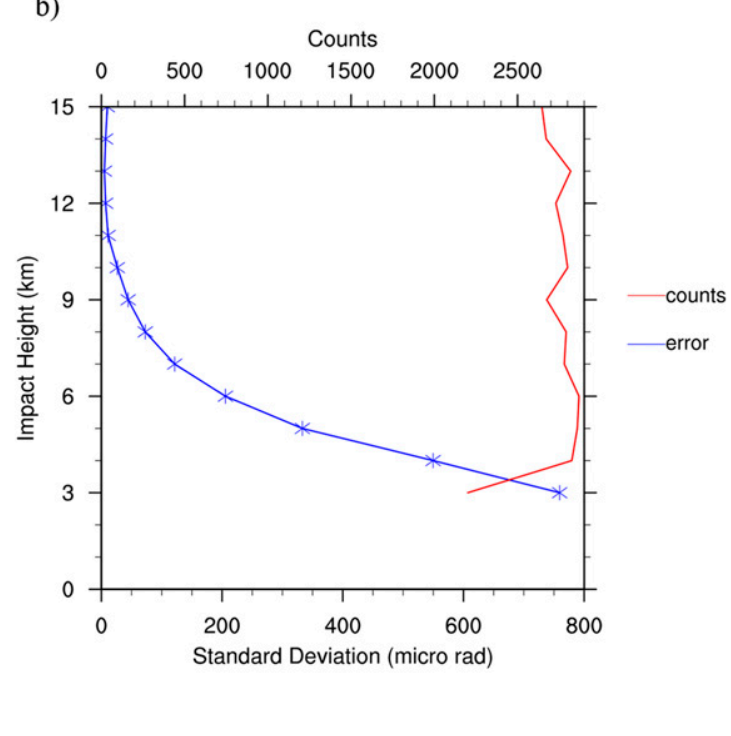

FIG. 2. (a) Refractivity standard deviations ( $N$-units) as a function of height $(\mathrm{km})$ calculated from the observation increments $(O-B)$ from the OSE (solid line) and from the OSSE before tuning (dashed line), and the specified explicit error added in the observation simulation (dotted line). Values are plotted for the mean of the COSMIC satellites operational in 2014. Explicit errors for the COSMIC-2 satellites are based on this mean error. (b) Bending angle standard deviation $(\mu \mathrm{rad})$ as a function of the impact height $(\mathrm{km})$. This error includes measurement, representativeness, and forward model errors.

communication). In the OSSE, deeper penetration was accomplished by increasing the statistical quality control threshold for observation rejection below $3 \mathrm{~km}$. This threshold is compared to the difference between the observed refractivity and the corresponding simulated value, and thus, increasing this threshold emulates the larger percentage of COSMIC-2 observations that are expected to reach the lowest few kilometers, particularly in the tropics (Figs. 4a,b).

We ran three different experiments. First, a control OSSE (CTL) assimilated all the observations that were operationally assimilated in 2014, except for RO observations. Simulated COSMIC-2 RO refractivity soundings without explicit errors were assimilated in RO_PERF, and error-added COSMIC-2 RO refractivity soundings were assimilated in the RO_ERR experiment. (No other $\mathrm{RO}$ observations were assimilated in the experiments with COSMIC-2.) Seven-day experimental forecasts begin at 0000 UTC from 1 August to 30 September 2006. The first month is used for model spinup, and verification is done for 1-30 September 2006.

In this study, we report statistical significance at the 95\% level (i.e., based on confidence intervals that are plotted from $2.5 \%$ to $97.5 \%$ ), assuming the mean has an approximate Student's $t$ distribution and ignoring any serial correlations. With a longer verification period, somewhat smaller-impact magnitudes would be statistically significant. Both the present study and the previous study by Cucurull et al. (2017) used a 2-month study period, but determined verification statistics over the last 30 and 41 days of the period, respectively. In the current study, a spinup period of 1 month is used to eliminate all traces of system spinup. However, results would not be qualitatively affected if the last 40 or 45 days of the study period were used for verification.

\section{Impact of perfect RO soundings}

Anomaly correlation (AC) skill for the 500-hPa geopotential heights is shown in Figs. $5 a$ and $5 b$ for the Northern Hemisphere $\left(\mathrm{NH} ; 20^{\circ}-80^{\circ} \mathrm{N}\right)$ and Southern Hemisphere ( $\left.\mathrm{SH} ; 20^{\circ}-80^{\circ} \mathrm{S}\right)$ extratropics, respectively. Positive impact with RO assimilation is found in both latitudinal ranges. The benefits from adding perfect $\mathrm{RO}$ observations in RO_PERF over the CTL are larger in the $\mathrm{SH}$ than in the $\mathrm{NH}$, which is consistent with the results obtained with real RO observations (Cucurull 2010; Cucurull et al. 2013). Forecast results are statistically significant at the $95 \%$ confidence level until day 4 in the $\mathrm{NH}$ and for all the forecast lead times in the $\mathrm{SH}$. Benefits from the assimilation of RO observations on 500-hPa geopotential height forecasts are overall lower than in Cucurull et al. (2017), where an older OSSE configuration was used. The use of a more state-of-the art data assimilation system, along with a better characterization of the error structures of the observations in 
Lat: $34.89 \mathrm{~N}$

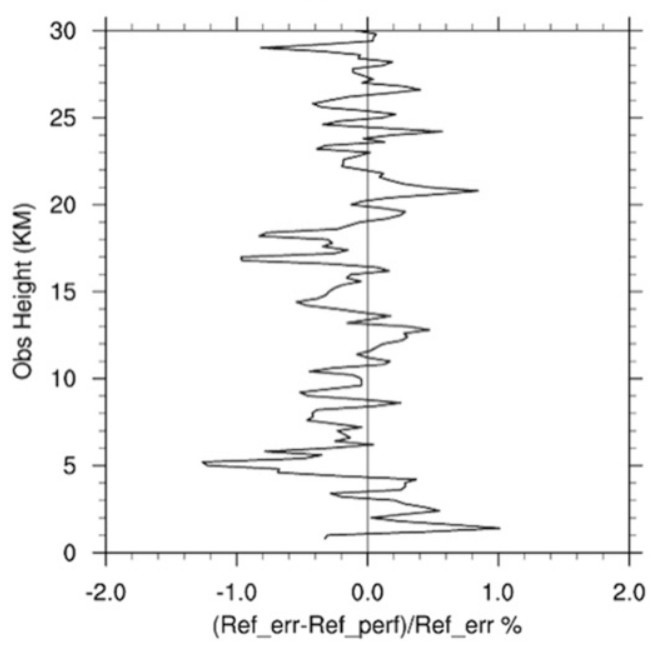

Lat: $62.59 \mathrm{~N}$

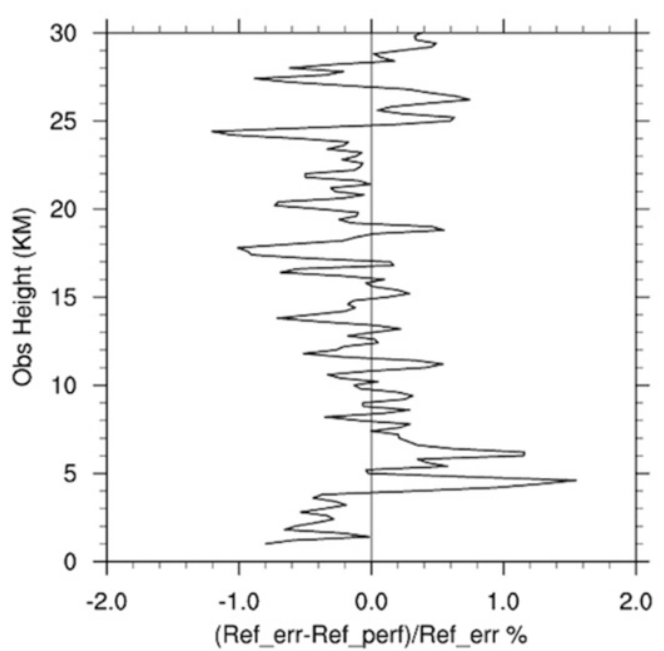

Lat: $9.07 \mathrm{~S}$

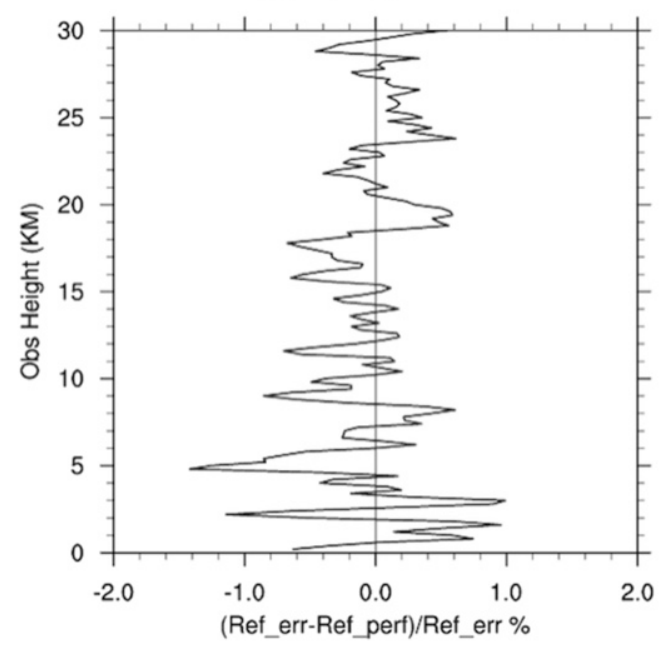

Lat: $49.38 \mathrm{~S}$

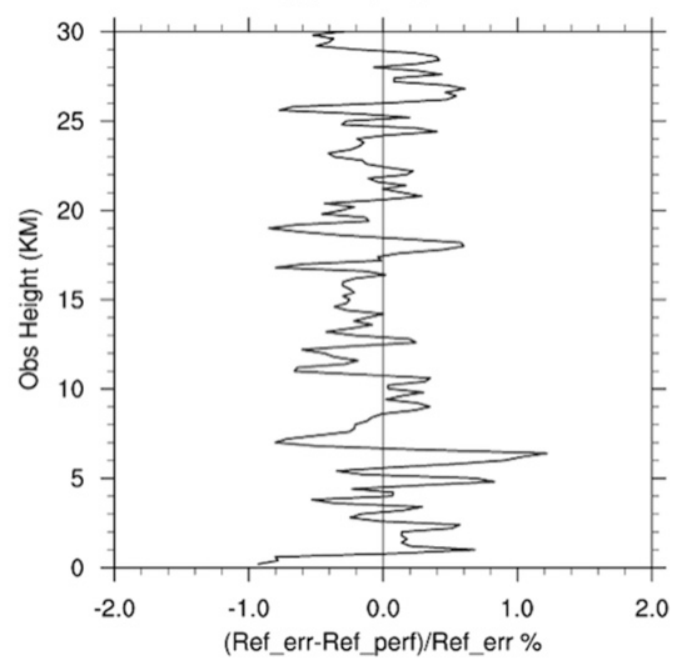

FIG. 3. Difference (in percent) between RO observations with and without explicit errors added to the simulated observations for four RO profiles.

our control experiment, might have resulted in a lower impact of RO in improving this metric of weather forecast skill. For example, at day 5, the use of RO improves the AC score by $0.2 \%$ over the control in the $\mathrm{NH}$ and by $1.3 \%$ in the SH (Figs. 6a,b). These values are lower than the values of $1.1 \%(\mathrm{NH})$ and $2.7 \%(\mathrm{SH})$ reported in the OSSE study conducted by Cucurull et al. (2017).

Similar benefits from the use of RO are obtained for the temperature field. As an example, anomaly correlation skill for the $250-\mathrm{hPa}$ vertical level is shown in Figs. $7 \mathrm{a}$ and $7 \mathrm{~b}$ for the $\mathrm{NH}$ and $\mathrm{SH}$, respectively. Improvements over CTL are consistently positive across the several forecast lead times and are larger in the SH.
Temperature biases in the analyses are also reduced with the assimilation of almost unbiased RO profiles in RO_PERF. As shown in Fig. 8b, the CTL-averaged analysis has a warm bias in the mid-lower troposphere and primarily a cold bias above $300 \mathrm{hPa}$, except for the $\sim 100-200-\mathrm{hPa}$ vertical range in the $\mathrm{SH}$ and the upper $(<150 \mathrm{hPa})$ tropical atmosphere, where the model shows warm biases. The assimilation of perfect RO observations in RO_PERF results in an overall reduction of both the warm and cold analyses biases (Fig. 8c). In particular, notice the reduction in the overall bias in the $\mathrm{SH}$. This finding is consistent with the earlier global OSSE results from Cucurull et al. (2017), where an overall reduction of systematic temperature 
a)

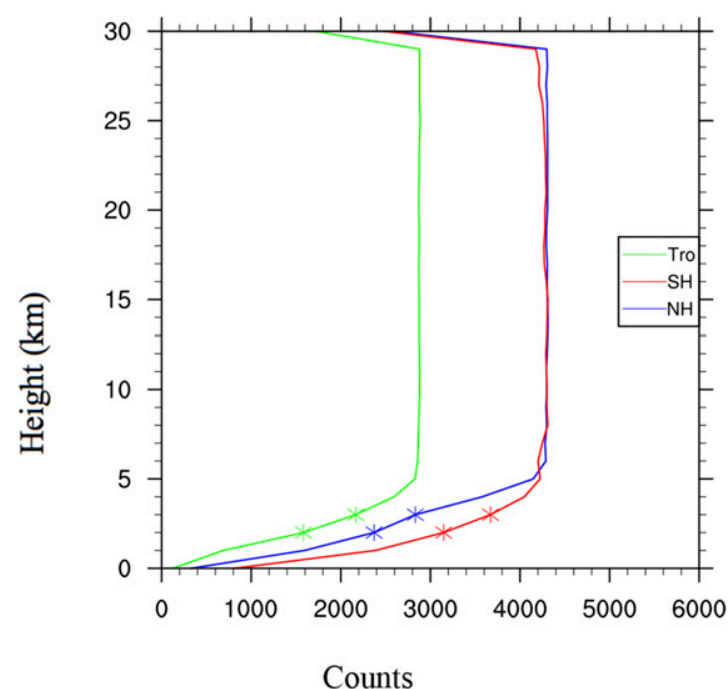

b) COSMIC

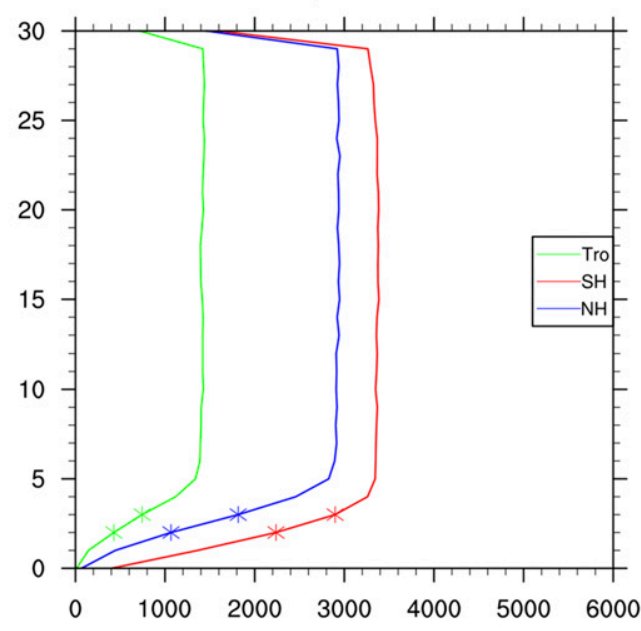

Counts

FIG. 4. Number of refractivity observations in (a) simulated experiments with COSMIC-2 and (b) real experiments with COSMIC as a function of the vertical height for a 1-week period. A larger percentage of observations reach the lower troposphere in the experiments with COSMIC-2.

analysis error was found with the assimilation of RO observations.

Positive impact with the assimilation of RO profiles is also found for the upper- and lower-level winds. Root-mean-square (rms) wind errors as a function of the forecast hour for the $200-\mathrm{hPa}$ vertical level are shown in Figs. 9a, 9c, and 9e for the NH, tropics (TR; $20^{\circ} \mathrm{S}-20^{\circ} \mathrm{N}$ ), and $\mathrm{SH}$ latitudinal ranges, respectively. The reduction in rms wind errors is larger in the TR and $\mathrm{SH}$, with a maximum improvement of $0.72 \mathrm{~m} \mathrm{~s}^{-1}$ for the 48-h forecast tropical winds. The impact of RO in reducing global rms wind errors is similar to the results a)

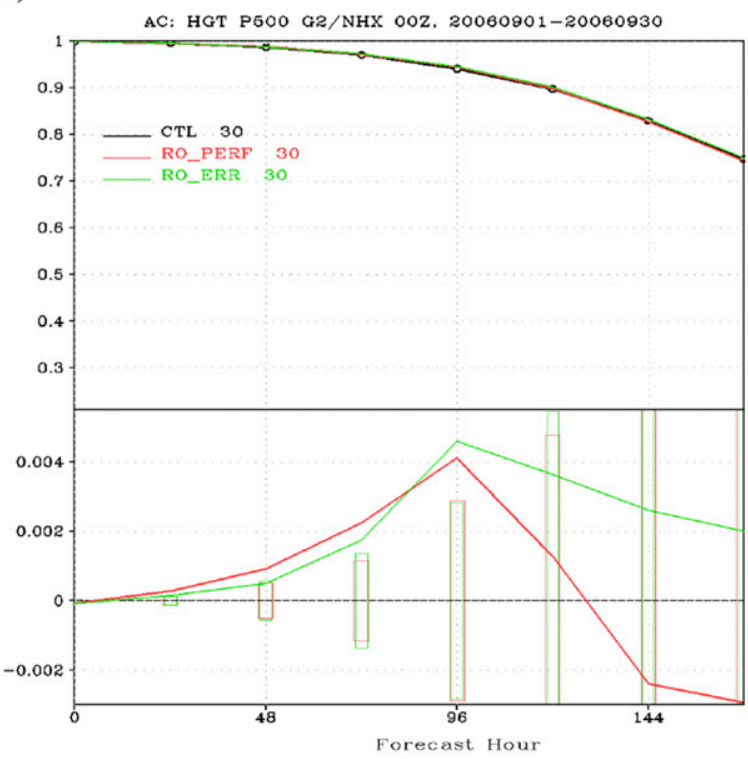

b)

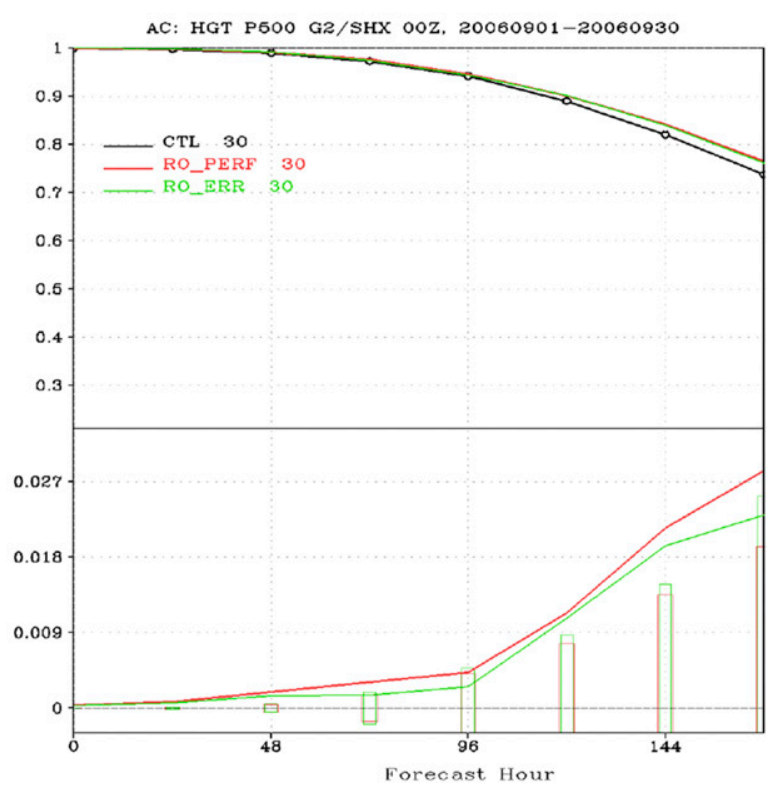

FIG. 5. Anomaly correlation score for the 500-hPa geopotential heights for CTL (black), RO_PERF (red), and RO_ERR (green) for (a) NH and (b) SH. Lower parts of each panel show differences with respect to CTL, with positive being an improvement. Bars show limits of statistical significance at the $95 \%$ confidence level; values above bars are statistically significant. 
a)

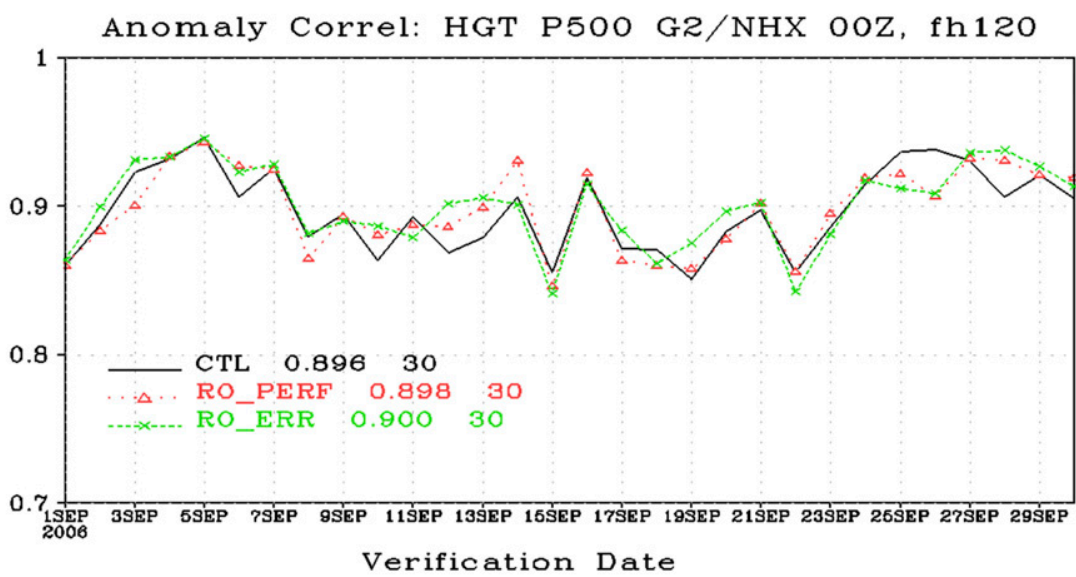

b)

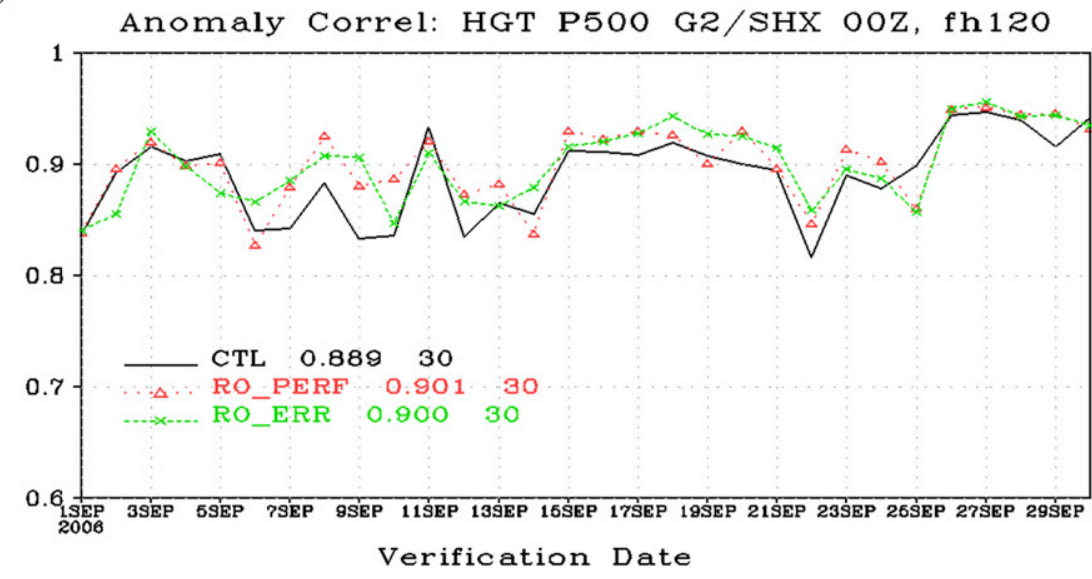

FIG. 6. Five-day anomaly correlation score for the 500-hPa geopotential heights for CTL (black), RO_PERF (red), and RO_ERR (green) for (a) NH and (b) SH.

of Cucurull et al. (2017), although the impact is now slightly larger in the TR. It is expected that the improved representation of background error covariances in the hybrid ensemble-variational DA system would enable greater benefit from the use of additional mass field observations (such as RO profiles) to improve the upper-level tropical winds. Differences between RO_PERF and CTL are statistically significant at the $95 \%$ confidence level until day 4 in the $\mathrm{NH}$, and these differences extend across the different forecast lead times in the TR and SH. Wind errors (and typical wind speeds) in the CTL are overall lower at $850 \mathrm{hPa}$, and so is the impact of RO, both in magnitude and percentage (Figs. 9b,d,f). For the lower-level winds, the impact of RO is similar to the results of Cucurull et al. (2017), and the largest reduction in rms wind errors is found in the SH $\left(\sim 0.3 \mathrm{~m} \mathrm{~s}^{-1}\right.$ at day 6$)$. At $850 \mathrm{hPa}$, differences between RO_PERF and CTL are statistically significant at the $95 \%$ confidence level in the TR and $\mathrm{SH}$ for all the forecast lead times, and only for days 2-4 in the NH.

The assimilation of RO observations in RO_PERF also results in an improvement of the moisture field. As an example, Fig. 10 shows the relative humidity rms forecast error as a function of the forecast hour at the $500-\mathrm{hPa}$ vertical pressure level. The use of RO decreases the rms errors for all latitudinal ranges and forecast lead times, and the impact is larger in the TR and SH. In the TR, improvements due to the assimilation of RO are largest during the first $72 \mathrm{~h}$. The impact of $\mathrm{RO}$ in decreasing rms error for the relative humidity field is also positive at the lower-pressure levels, although the impact is, in general, smaller (not shown). As in the case of the temperature field, moisture analyses biases are also reduced with the assimilation of RO profiles (Figs. 9f,g). 
a)

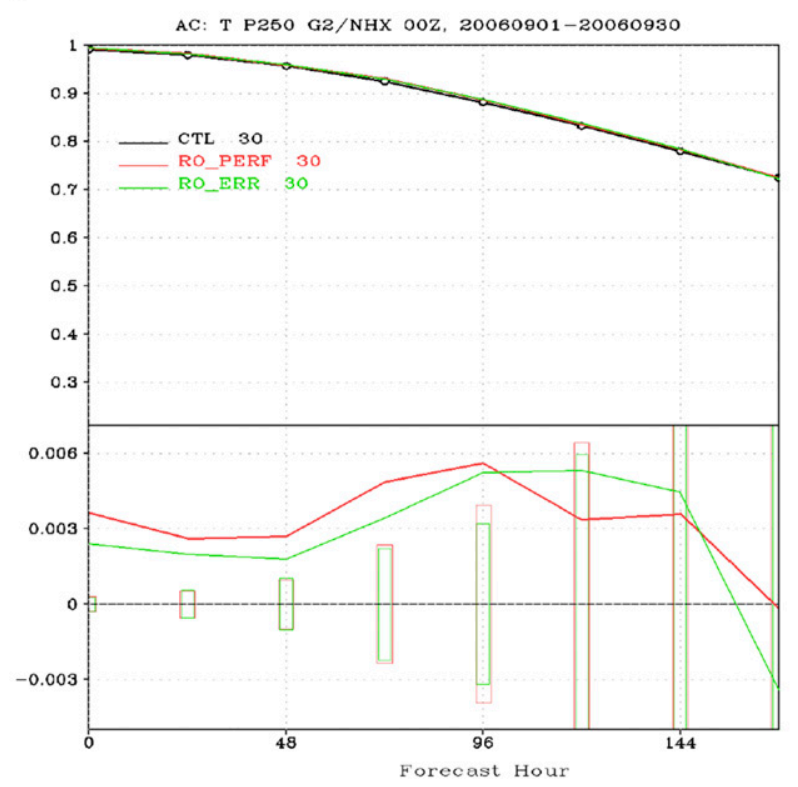

b)

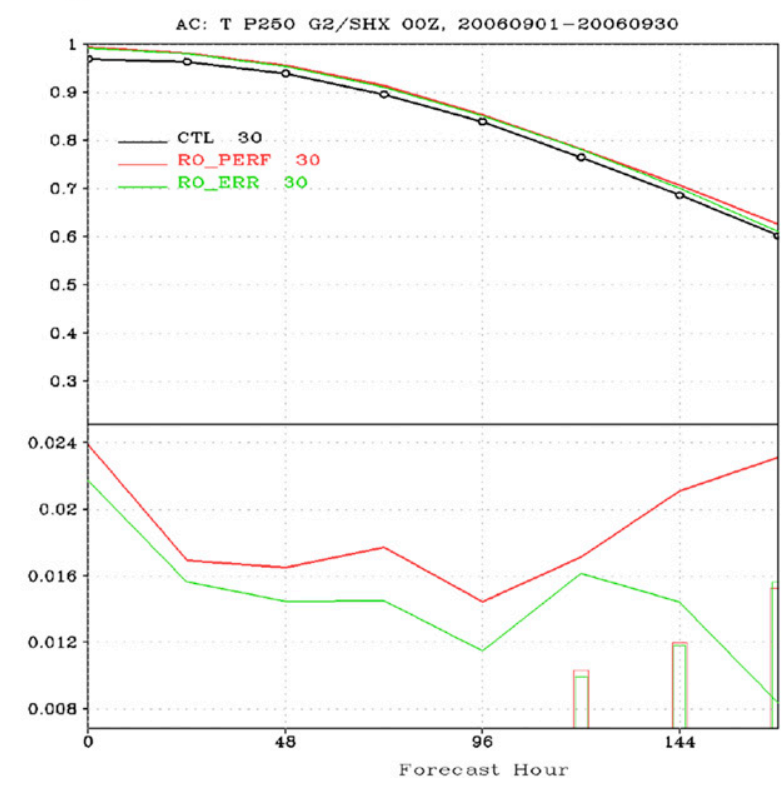

FIG. 7. Anomaly correlation score for the 250-hPa temperature field for CTL (black), RO_PERF (red), and RO_ERR (green) for (a) NH and (b) SH. Lower parts of each panel show differences with respect to CTL, with positive being an improvement. Bars show limits of statistical significance at the $95 \%$ confidence level; values above bars are statistically significant.

\section{Impact of error-added RO soundings}

As with the use of perfect RO profiles, the assimilation of explicitly error-added RO observations in RO_ERR results in an increase of the 500-hPa geopotential height AC score in the extratropics (Figs. 5a,b). At day 5, RO increases the AC skill in RO_ERR over the CTL by $0.4 \%$ in the $\mathrm{NH}$ and $1.2 \%$ in the SH (Figs. 6a,b). Differences between RO_ERR and CTL forecasts are statistically significant at the $95 \%$ confidence level at days 1,3 , and 4 in the $\mathrm{NH}$ and through the entire period, excluding days 3, 4, and 7, in the SH. Differences in AC between experiments using perfect and error-added observations are small, with the use of perfect observations resulting in a slightly higher AC score, and not statistically significant beyond day 2 in the $\mathrm{NH}$ and beyond day 3 in the SH. Yet, these small differences between RO_PERF and RO_ERR cause the differences between CTL and RO_ERR not to be statistically significant at days 3, 4, and 7 in the $\mathrm{SH}$ and at day 2 in the $\mathrm{NH}$, but statistically significant between CTL and RO_PERF for the same forecast lead times.

Similar benefits from RO assimilation are found for the temperature field. The use of RO in RO_ERR improves the $250-\mathrm{hPa}$ temperature AC score over the CTL experiment (Figs. 7a,b). Differences between RO_ERR and CTL are statistically significant at the $95 \%$ confidence level until day 4 in the NH and until day 6 in the $\mathrm{SH}$. As found with RO_PERF, the RO impact is larger in the SH than in the NH. Similar to the results for the geopotential heights, RO_PERF performs slightly better than RO_ERR, although differences are generally small and not statistically significant at the $95 \%$ confidence level beyond day 3 .

The largest improvement in reducing upper- and lower-level rms wind errors due to the assimilation of RO profiles is found in the TR and the SH (Figs. 9b,d,f), and differences are statistically significant for most of the forecast lead times. (In the $\mathrm{NH}$, differences are generally smaller and only statistically significant at the analysis time and at day 4.) Once again, the positive impact of RO is slightly lower than when the perfect RO profiles were used in RO_PERF. In the NH, differences between RO_PERF and RO_ERR are statistically significant until day 2 for the upper- and lower-level winds. In the $\mathrm{SH}$, these differences are statistically significant until day 2 for the lower-level winds and until day 4 for the upper-level winds. Differences between RO_PERF and RO_ERR are statistically significant for most of the forecast lead times in the tropical latitudes.

The rms moisture errors also decrease with the assimilation of RO profiles in RO_ERR (Figs. 10a-c). As with the other fields, the use of error-added RO observations tends to generate smaller improvements than with the assimilation of perfect RO soundings. However, differences between RO_ERR and RO_PERF are generally small and not statistically significant at the 
a)

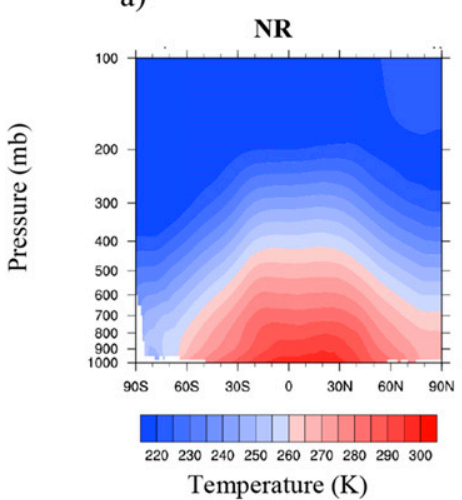

e)

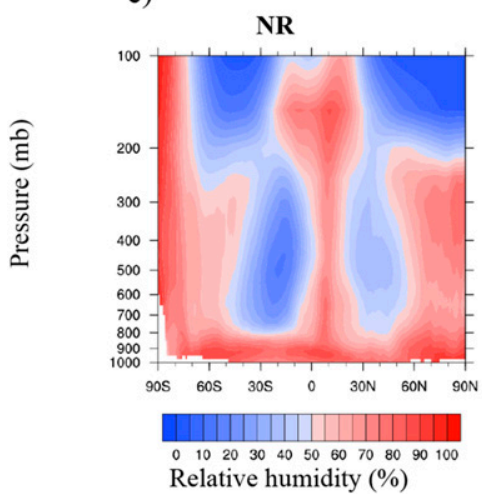

b)

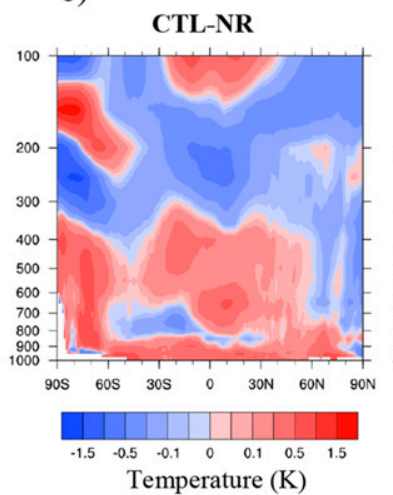

f)

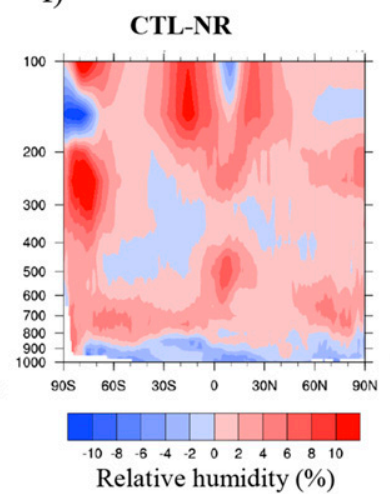

c)

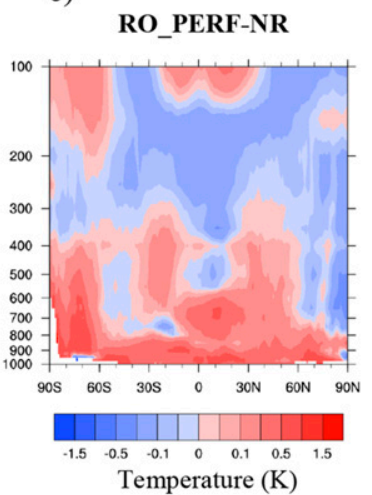

g)

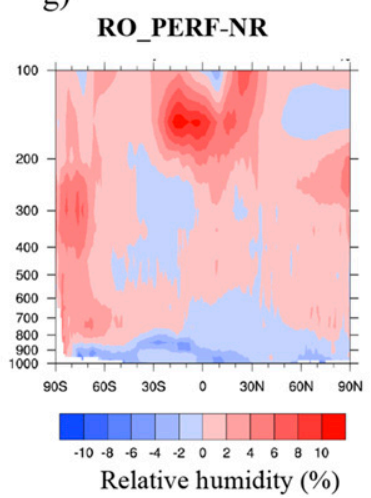

d) RO_ERR-NR

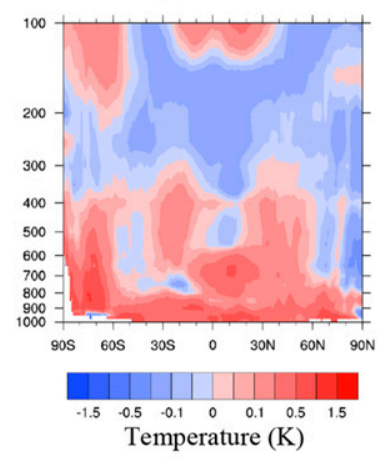

h)

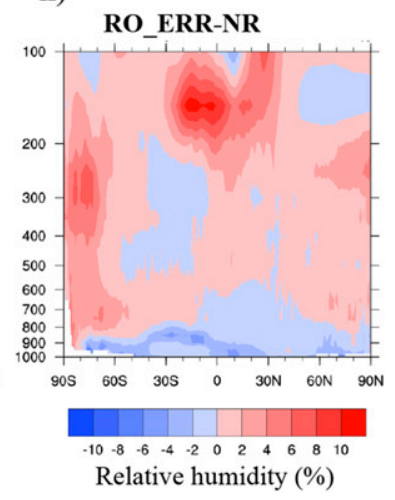

FIG. 8. Vertical cross section of the (a)-(d) systematic temperature analysis error and (e)-(h) relative humidity analysis error.

$95 \%$ confidence level past the first $24-48$ forecast hours. Finally, and as it was found in section 3, temperature (Fig. 8d) and humidity (Fig. 8h) biases in the analyses are overall reduced due to the assimilation of almost unbiased RO observations.

\section{Conclusions}

NOAA conducted comprehensive experiments with a previously existing global OSSE system to determine the potential value of RO constellations for current operational NWP systems (Cucurull et al. 2017). Results have been extended in this study to a newly developed OSSE system that includes a higher-resolution nonhydrostatic nature run, a state-of-the-art operational forecast model and hybrid ensemble data assimilation system, and realistic simulated observation errors.

The new OSSE system, while state of the art, is still imperfect, and some caveats apply to our findings. Limitations of the nature run are summarized by Boukabara et al. (2016), those of the observation simulations by Boukabara et al. (2018a), and those of the calibration of the overall system by Boukabara et al. (2018b). A particular limitation of the current experiments is the use of verification scores over a single 1-month period. It would be valuable to repeat our experiments in the future for different times of year and longer periods to examine the sensitivity of our results to the choice of the study period.

In general, increasing the number of assimilated ROs to 12 COSMIC-2 receiving satellites improves global weather forecasts. The improvement is greatest in the Southern Hemisphere extratropics and tropics. As a summary, the impact of RO observations can be expressed in terms of the increase in the length of useful forecasts. In experiments with explicit errors, these increases-quantified as the increase in forecast time to reach an anomaly correlation value of 0.8 for the 500-hPa geopotential heights in the extratropics or to reach a root-mean-square error of $6 \mathrm{~m} \mathrm{~s}^{-1}$ for the 200-hPa-level winds in the tropics-were found to be $0.6 \mathrm{~h}$ in the Northern Hemisphere extratropics (a $0.4 \%$ improvement), $5.9 \mathrm{~h}$ in the Southern Hemisphere extratropics (a significant $4.0 \%$ improvement), and $12.1 \mathrm{~h}$ in the tropics (a very substantial $28.4 \%$ improvement).

As compared to previous OSSE work with RO observations using a simplified OSSE system, our findings indicate smaller benefits in the extratropics from the assimilation of $12 \mathrm{RO}$ satellites in terms of anomaly 
a)

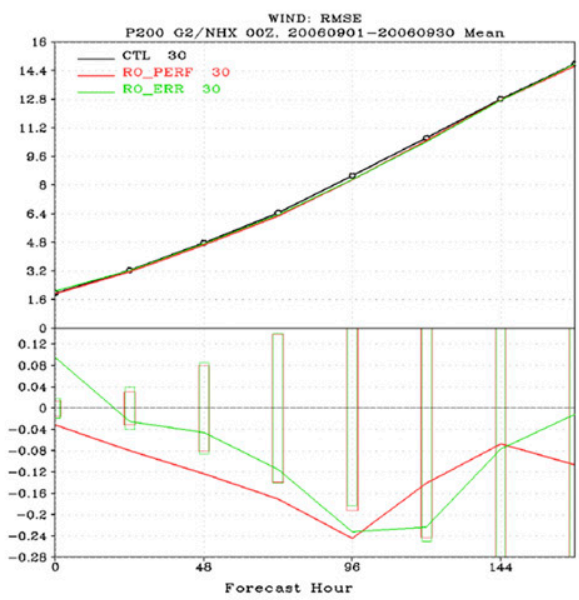

c)

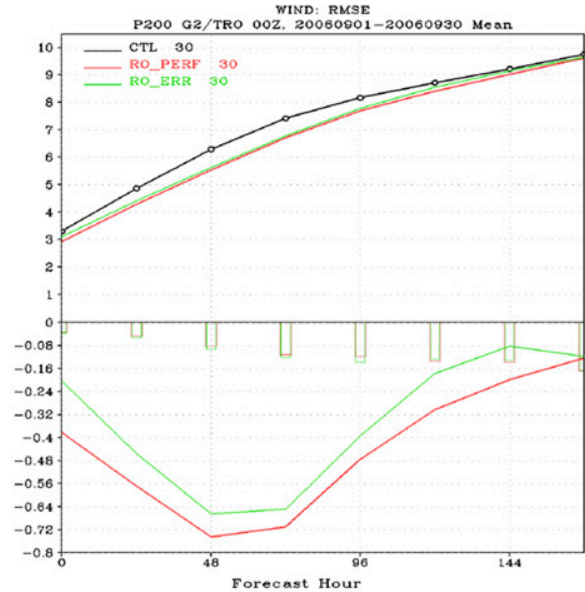

e)

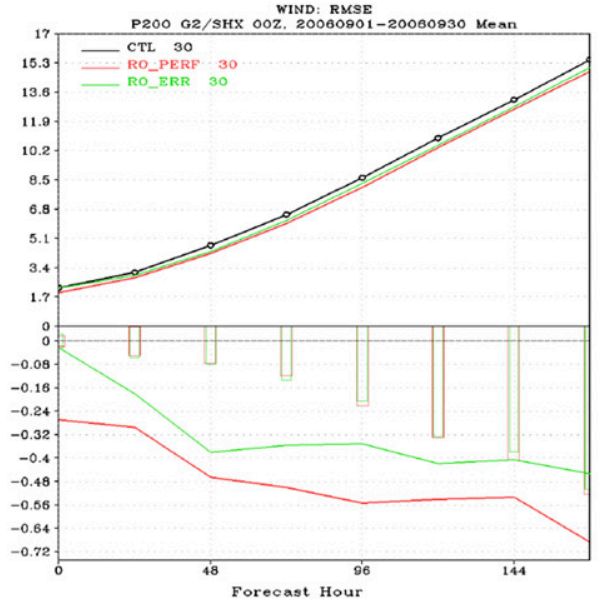

b)

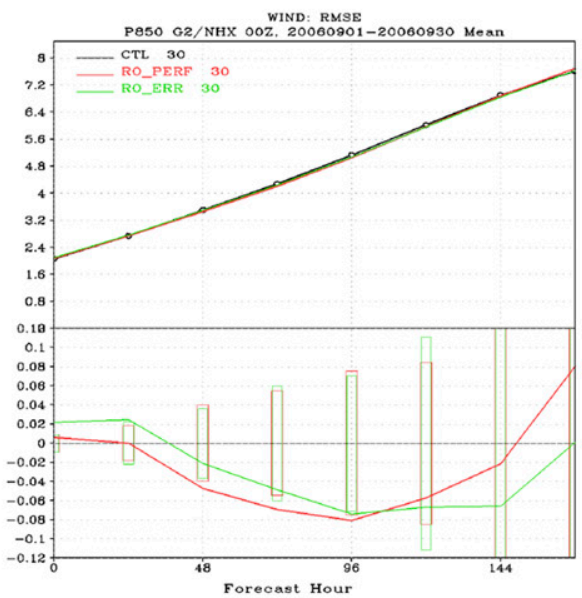

d)

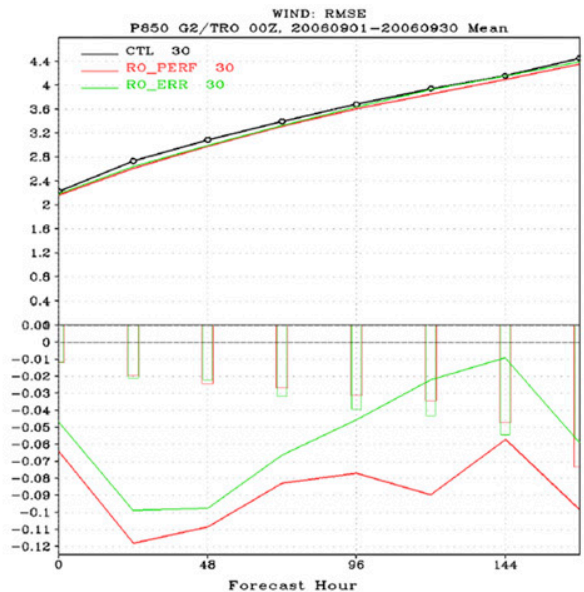

f)

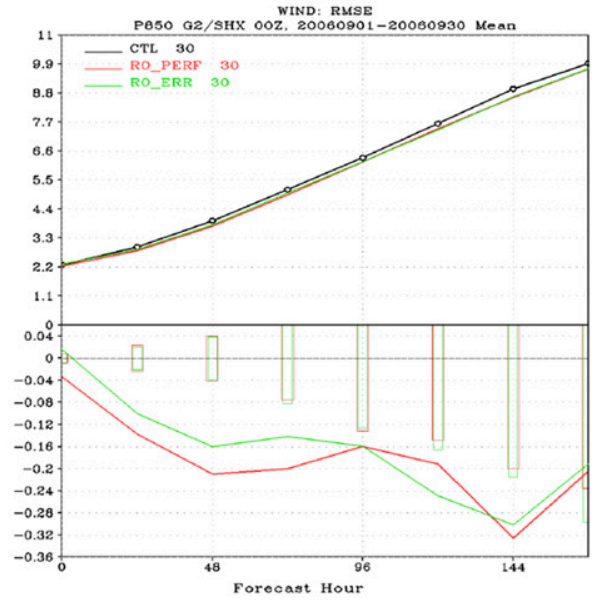

FIG. 9. (left) Upper (200 hPa) and (right) lower $(850 \mathrm{hPa})$ rms wind errors (in $\left.\mathrm{m} \mathrm{s}^{-1}\right)$ for the (a),(b) NH, (c),(d) TR, and (e),(f) SH as a function of the forecast hour for CTL (black), RO_PERF (red), and RO_ERR (green). 
a)

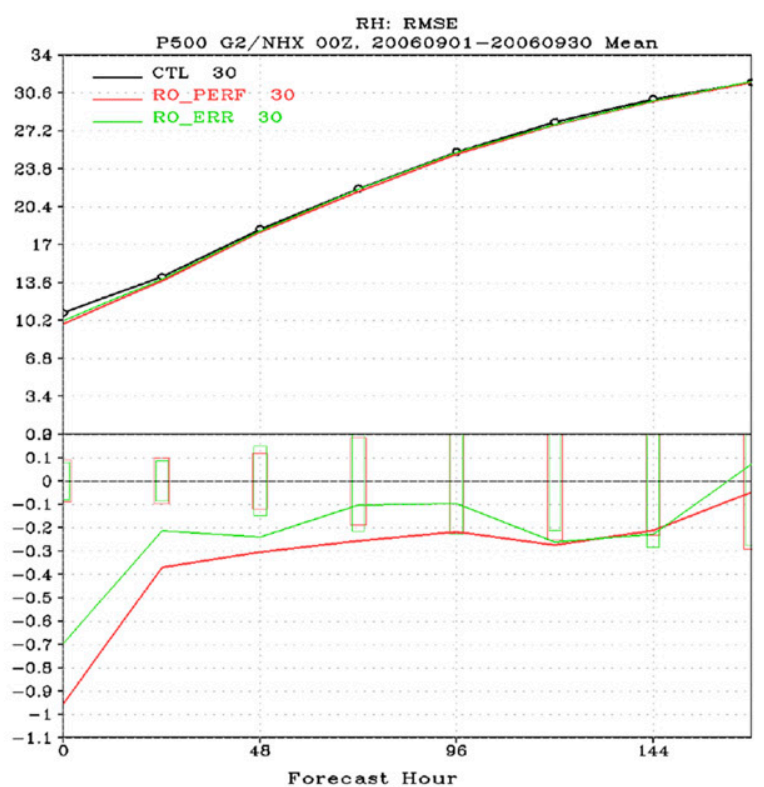

c)

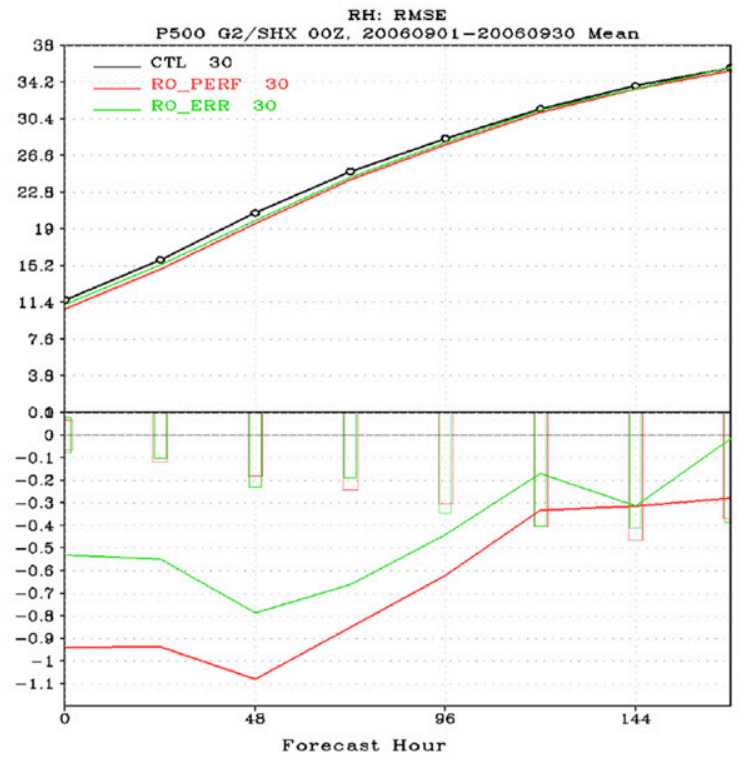

correlation score. However, the impact in reducing global rms wind errors remains similar, suggesting that a more state-of-the-art OSSE configuration, with a better forecast model and data assimilation system, might continue to benefit from the use of new and accurate RO observations to improve wind forecasts, particularly in the tropics. An overall reduction of systematic temperature and relative humidity analysis errors was found with the assimilation of RO soundings, which is consistent with previous studies with real and simulated observations. b)

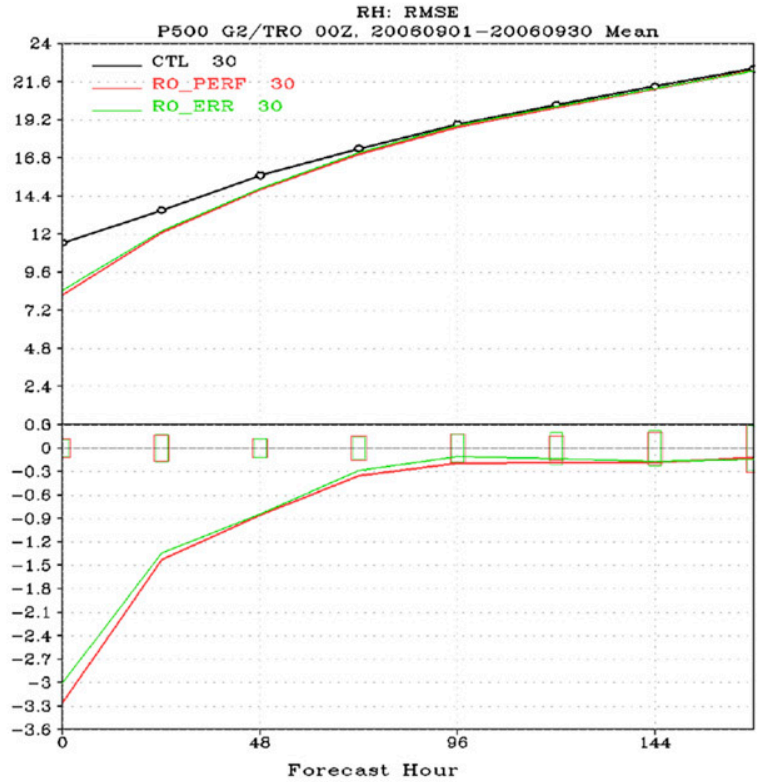

FIG. 10. The 500-hPa rms errors for the relative humidity field (in percent) for (a) $\mathrm{NH}$, (b) TR, and (c) $\mathrm{SH}$ as a function of the forecast hour for CTL (black), RO_PERF (red), and RO_ERR (green).

When appropriate error statistics are added to the global observing system, the impact of adding these explicit errors to the simulated RO observations was found to be small and, in general, not statistically significant at the $95 \%$ confidence level. The benefits of adding 12 RO receiving satellites to the global observing system exist, whether or not explicit errors are added to a baseline of perfect simulated $\mathrm{RO}$ soundings.

Further development of the new state-of-the-art OSSE system for weather forecasting applications is 
underway at NOAA. As the new OSSE system is being refined, we are improving the simulation of RO observations (e.g., use of more accurate forward operators to simulate and assimilate bending angle instead of refractivity), and we plan to repeat some of the RO experiments and extend our work to the evaluation of additional observing platforms.

Acknowledgments. The authors thank Jack Woollen for generating the templates to simulate the COSMIC-2 observations and to Dr. Sean PF Casey and the rest of the NOAA OSSE team to help simulate observations from the nature run. This study was conducted by NOAA in response to the H.R. 353, the "Weather Research and Forecasting Innovation Act of 2017" (Public Law 115-25, https://www.congress.gov/bill/115th-congress/house-bill/ 353/text), under the auspices of NOAA's Quantitative Observing System Assessment Program (QOSAP). According to section 107(d)(1) of the Act: "Not later than 30 days after the date of the enactment of this Act, the Assistant Administrator for Oceanic and Atmospheric Research shall complete an Observing System Simulation Experiment [OSSE] to assess the value of data from Global Navigation Satellite System Radio Occultation."

\section{REFERENCES}

Anlauf, H., D. Pingel, and A. Rhodin, 2011: Assimilation of GPS radio occultation data at DWD. Atmos. Meas. Tech., 4, 11051113, https://doi.org/10.5194/amt-4-1105-2011.

Anthes, R. A., and Coauthors, 2008: The COSMIC/FORMOSAT-3 Mission: Early results. Bull. Amer. Meteor. Soc., 89, 313-334, https://doi.org/10.1175/BAMS-89-3-313.

Aparicio, J. M., and G. Deblonde, 2008: Impact of the assimilation of CHAMP refractivity profiles in Environment Canada global forecasts. Mon. Wea. Rev., 136, 257-275, https://doi.org/ 10.1175/2007MWR1951.1.

Atlas, R., 1997: Atmospheric observations and experiments to assess their usefulness in data assimilation. J. Meteor. Soc. Japan, 75, 111-130, https://doi.org/10.2151/jmsj1965.75.1B_111.

_ E. Kalnay, and M. Halem, 1985: Impact of satellite temperature sounding and wind data on numerical weather prediction. Opt. Eng., 24, 242341, https://doi.org/10.1117/12.7973481.

_ (OSSEs) to evaluate the potential impact of an optical autocovariance wind lidar (OAWL) on numerical weather prediction. J. Atmos. Oceanic Technol., 32, 1593-1613, https://doi.org/10.1175/ JTECH-D-15-0038.1.

— L. Bucci, B. Annane, R. Hoffman, and S. Murillo, 2015b: Observing system simulation experiments to assess the potential impact of new observing systems on hurricane forecasting. Mar. Technol. Soc. J., 49, 140-148, https://doi.org/10.4031/MTSJ.49.6.3.

Bauer, P., G. Radnóti, S. B. Healy, and C. Cardinali, 2014: GNSS radio occultation constellation observing system experiments. Mon. Wea. Rev., 142, 555-572, https://doi.org/10.1175/MWR-D-13-00130.1.

Bonavita, M., 2014: On some aspects of the impact of GPSRO observations in global numerical weather prediction. Quart. J. Roy. Meteor. Soc., 140, 2546-2562, https://doi.org/10.1002/qj.2320.
Boukabara, S.-A., and Coauthors, 2016: Community global observing system simulation experiment (OSSE) package (CGOP): Description and usage. J. Atmos. Oceanic Technol., 33, 1759-1777, https://doi.org/10.1175/JTECH-D-16-0012.1.

__, and Coauthors, 2018a: Community global observing system simulation experiment (OSSE) package (CGOP): Perfect observations simulation validation. J. Atmos. Oceanic Technol., 35, 207-226, https://doi.org/10.1175/ JTECH-D-17-0077.1.

— , and Coauthors, 2018b: Community global observing system simulation experiment (OSSE) package (CGOP): Assessment and validation of the OSSE system using an OSSE-OSE intercomparison of summary assessment metrics. J. Atmos. Oceanic Technol., 35, 2061-2078, https://doi.org/10.1175/ JTECH-D-18-0061.1.

Chen, Y., F. Weng, Y. Han, and Q. Liu, 2008: Validation of the Community Radiative Transfer Model by using CloudSat data. J. Geophys. Res., 113, D00A03, https://doi.org/10.1029/ 2007JD009561.

Cucurull, L., 2010: Improvement in the use of an operational constellation of GPS radio occultation receivers in weather forecasting. Wea. Forecasting, 25, 749-767, https://doi.org/ 10.1175/2009WAF2222302.1.

— , and J. C. Derber, 2008: Operational implementation of COSMIC observations into the NCEP's Global Data Assimilation System. Wea. Forecasting, 23, 702-711, https://doi.org/ 10.1175/2008WAF2007070.1.

_ , and R. A. Anthes, 2015: Impact of loss of U.S. microwave and radio occultation observations in operational numerical weather prediction in support of the U.S. data gap mitigation activities. Wea. Forecasting, 30, 255-269, https://oi.org/ 10.1175/WAF-D-14-00077.1.

— J. C. Derber, and R. J. Purser, 2013: A bending angle forward operator for global positioning system radio occultation measurements. J. Geophys. Res. Atmos., 118, 14-28, https:// doi.org/10.1029/2012JD017782.

- R. A. Anthes, and L.-L. Tsao, 2014: Radio occultation observations as anchor observations in numerical weather prediction models and associated reduction of bias corrections in microwave and infrared satellite observations. J. Atmos. Oceanic Technol., 31, 20-32, https://doi.org/10.1175/JTECHD-13-00059.1.

— R. Li, and T. Peevey, 2017: Assessment of radio occultation observations from the COSMIC-2 mission with a simplified observing system simulation experiment configuration. Mon. Wea. Rev., 145, 3581-3597, https://doi.org/10.1175/MWR-D16-0475.1.

Dee, D. P., 2005: Bias and data assimilation. Quart. J. Roy. Meteor. Soc., 131, 3323-3343, https://doi.org/10.1256/qj.05.137.

Ding, S., P. Yang, F. Weng, Q. Liu, Y. Han, P. van Delst, J. Li, and B. Baum, 2011: Validation of the Community Radiative Transfer Model. J. Quant. Spectrosc. Radiat. Transfer, 112, 1050-1064, https://doi.org/10.1016/j.jqsrt.2010.11.009.

Errico, R. M., R. Yang, N. Privé, K.-S. Tai, R. Todling, M. E. Sienkiewicz, and J. Guo, 2013: Development and validation of observing-system simulation experiments at NASA's Global Modeling and Assimilation Office. Quart. J. Roy. Meteor. Soc., 139, 1162-1178, https://doi.org/10.1002/qj.2027.

Halliwell, G. R., Jr., A. Srinivasan, V. Kourafalou, H. Yang, D. Willey, M. Le Hénaff, and R. Atlas, 2014: Rigorous evaluation of a fraternal twin ocean OSSE system for the open Gulf of Mexico. J. Atmos. Oceanic Technol., 31, 105-130, https://doi.org/10.1175/JTECH-D-13-00011.1. 
, V. Kourafalou, M. Le Hénaff, L. K. Shay, and R. Atlas, 2015 OSSE impact analysis of airborne ocean surveys for improving upper-ocean dynamical and thermodynamical forecasts in the Gulf of Mexico. Prog. Oceanogr., 130, 32-46, https://doi.org/ 10.1016/j.pocean.2014.09.004.

Healy, S. B., and J.-N. Thépaut, 2006: Assimilation experiments with CHAMP GPS radio occultation measurements. Quart. J. Roy. Meteor. Soc., 132, 605-623, https://doi.org/10.1256/qj.04.182.

_ - A. M. Jupp, and C. Marquardt, 2005: Forecast impact experiment with GPS radio occultation measurements. Geophys. Res. Lett., 32, L03804, https://doi.org/10.1029/2004GL020806.

Hoffman, R. N., and R. Atlas, 2016: Future observing system simulation experiments. Bull. Amer. Meteor. Soc., 97, 16011616, https://doi.org/10.1175/BAMS-D-15-00200.1.

Masutani, M., and Coauthors, 2006: Observing system simulation experiments at NCEP. NCEP Office Note 451, 34 pp., http:// www.lib.ncep.noaa.gov/ncepofficenotes/files/on451.pdf.

Poli, P., S. B. Healy, and D. P. Dee, 2010: Assimilation of global positioning system radio occultation data in the ECMWF ERA-Interim reanalysis. Quart. J. Roy. Meteor. Soc., 136, 1972-1990, https://doi.org/10.1002/qj.722.

Putman, W. M., A. M. da Silva, L. E. Ott, and A. Darmenov, 2014: Model configuration for the 7-km GEOS-5 nature run, Ganymed release (Non-hydrostatic $7 \mathrm{~km}$ global mesoscale simulation). GMAO Office Note 5 (version 1.0), 18 pp., https:// gmao.gsfc.nasa.gov/pubs/docs/Putman727.pdf.
A. Darmenov, A. da Silva, R. Gelaro, A. Molod, L. Ott, and M. J. Suarez, 2015: A 7-km non-hydrostatic global mesoscale simulation for OSSEs with the Goddard Earth Observing System model (GEOS-5). 19th Conf. on Integrated Observing and Assimilation Systems for the Atmosphere, Oceans, and Land Surface (IOAS-AOLS), Phoenix, AZ, Amer. Meteor. Soc., 3.1, https://ams.confex.com/ams/95Annual/webprogram/ Paper260701.html.

Rennie, M. P., 2010: The impact of GPS radio occultation assimilation at the Met Office. Quart. J. Roy. Meteor. Soc., 136, 116131, https://doi.org/10.1002/qj.521.

Rocken, C., Y.-H. Kuo, W. S. Schreiner, D. Hunt, S. Sokolovskiy, and C. McCormick, 2000: COSMIC system description. Terr. Atmos. Ocean. Sci., 11, 21-52, https://doi.org/10.3319/ TAO.2000.11.1.21(COSMIC).

Schreiner, W., S. Sokolovskiy, D. Hunt, C. Rocken, and Y.-H. Kuo, 2011: Analysis of GPS radio occultation data from the FORMOSAT-3/COSMIC and Metop/GRAS missions at CDAAC. Atmos. Meas. Tech., 4, 2255-2272, https://doi.org/ 10.5194/amt-4-2255-2011.

Zhu, Y., J. Derber, A. Collard, D. Dee, R. Treadon, G. Gayno, and J. A. Jung, 2014: Enhanced radiance bias correction in the National Centers for Environmental Prediction's Gridpoint Statistical Interpolation data assimilation system. Quart. J. Roy. Meteor. Soc., 140, 1479-1492, https://doi.org/ 10.1002/qj.2233. 